\title{
Contribution of dietary starch to hepatic and systemic carbohydrate fluxes in European seabass (Dicentrarchus labrax L.)
}

\author{
Ivan Viegas ${ }^{1,2 *}$, João Rito ${ }^{1,2}$, Ivana Jarak $^{1}$, Sara Leston ${ }^{2,3}$, Albert Caballero-Solares ${ }^{4}$, Isidoro Metón ${ }^{5}$, \\ Miguel A. Pardal ${ }^{2}$, Isabel V. Baanante ${ }^{5}$ and John G. Jones ${ }^{1}$ \\ ${ }^{1}$ CNC - Center for Neuroscience and Cell Biology, University of Coimbra, Largo Marquês de Pombal, 3004-517 Coimbra, \\ Portugal \\ ${ }^{2}$ CFE - Center for Functional Ecology, Department Life Sciences, University of Coimbra, Calcada Martins de Freitas, \\ 3000-456 Coimbra, Portugal \\ ${ }^{3}$ CEF - Center for Pharmaceutical Studies, Pharmacy Faculty, University of Coimbra, Azinhaga de Santa Comba, \\ 3000-548 Coimbra, Portugal \\ ${ }^{4}$ Departament d'Ecologia, Facultat de Biologia, Universitat de Barcelona, Avenida Diagonal 645, O8028 Barcelona, Spain \\ ${ }^{5}$ Departament de Bioquímica i Biologia Molecular, Facultat de Farmàcia, Universitat de Barcelona, Joan XXIII s/n, \\ 08028 Barcelona, Spain
}

(Submitted 19 September 2014 - Final revision received 8 January 2015 - Accepted 4 February 2015 - First published online 2 April 2015)

\section{Abstract}

In the present study, the effects of partial substitution of dietary protein by digestible starch on endogenous glucose production were evaluated in European seabass (Dicentrarchus labrax). The fractional contribution of dietary carbohydrates $v$. gluconeogenesis to blood glucose appearance and hepatic glycogen synthesis was quantified in two groups of seabass fed with a diet containing $30 \%$ digestible starch (DS) or without a carbohydrate supplement as the control (CTRL). Measurements were performed by transferring the fish to a tank containing water enriched with $5 \%{ }^{2} \mathrm{H}_{2} \mathrm{O}$ over the last six feeding days, and quantifying the incorporation of ${ }^{2} \mathrm{H}$ into blood glucose and hepatic glycogen by ${ }^{2} \mathrm{H}$ NMR. For CTRL fish, gluconeogenesis accounted for the majority of circulating glucose while for the DS fish, this contribution was significantly lower (CTRL 85 (SEM 4) \% $v$. DS 54 (SEM 2) \%; $P<0 \cdot 001$ ). Hepatic glycogen synthesis via gluconeogenesis (indirect pathway) was also significantly reduced in the DS fish, in both relative (CTRL 100 (SEM 1) \% $v$. DS 72 (SEM 1 ) \%; $P<0 \cdot 001$ ) and absolute terms (CTRL 28 (SEM 1) $v$. DS 17 (SEM 1) $\mu \mathrm{mol} / \mathrm{kg}$ per h; $P<0 \cdot 001$ ). A major fraction of the dietary carbohydrates that contributed to blood glucose appearance (33 (SEM 1)\% of the total 47 (SEM 2) \%) had undergone exchange with hepatic glucose 6-phosphate. This indicated the simultaneous activity of hepatic glucokinase and glucose 6-phosphatase. In conclusion, supplementation of digestible starch resulted in a significant reduction of gluconeogenic contributions to systemic glucose appearance and hepatic glycogen synthesis.

Key words: ${ }^{2} \mathrm{H}_{2} \mathrm{O}$ : Gluconeogenesis: Endogenous glucose production: Glucokinase: Starch utilisation

In aquaculture, substituting costly fishmeal with less expensive plant-derived carbohydrate $(\mathrm{CHO})$ reduces feed input costs. The provision of dietary $\mathrm{CHO}$ to carnivorous fish such as the European seabass (Dicentrarchus labrax L.) may also have environmental benefits since $\mathrm{CHO}$ utilisation can potentially spare the catabolism of dietary amino acids to glucose and nitrogenous waste ${ }^{(1)}$. Dietary $\mathrm{CHO}$ influences growth, feed utilisation and deposition of nutrients according to species, quantity, origin and pre-treatment for improving digestibility $^{(2-4)}$. The effects of partial substitution of dietary protein by plant-derived $\mathrm{CHO}$ on food conversion efficiency and nutrient digestibility sources have been tested in seabass ${ }^{(5-7)}$. In addition, its effects on energy retention and maintenance requirements ${ }^{(8)}$ as well as the activity of key CHO-metabolising enzymes ${ }^{(6,9)}$ have been studied. These studies have suggested that, on the one hand, carnivorous fish are able to up-regulate their capacity for hepatic glucose utilisation through the increased expression of gateway enzymes such as glucokinase when fed with a high-CHO diet. However, on the other hand, supplementation of fish feed with up to $30 \%$ starch has not been shown to alter the overall protein efficiency ratio or nitrogen retention in seabass $^{(7)}$. This is despite the high apparent digestibility coefficient of starch (especially gelatinised) for this species ${ }^{(2)}$,

Abbreviations: CHO, carbohydrate; CTRL, control; DS, digestible starch; FBPase, fructose-1,6-bisphosphatase; G6P, glucose 6-phosphate; G6Pase, glucose 6phosphatase; GDH, glutamate dehydrogenase; GK, glucokinase; PFK-1, 6-phosphofructo 1-kinase; PW, plasma water.

*Corresponding author: I. Viegas, fax +351 231249188, email iviegas@ci.uc.pt 
suggesting that there is substantial absorption of glucose during feeding with starch-supplemented diets. Absorbed glucose can contribute to systemic glucose appearance, thereby potentially reducing the demand for endogenous glucose production via gluconeogenesis. Since amino acids are considered to be the principal source of gluconeogenic carbons in carnivorous fish ${ }^{(8,10)}$, a reduction in gluconeogenic activity would directly reduce the generation of nitrogenous waste.

A novel analysis of hepatic glucose and glycogen metabolism using ${ }^{2} \mathrm{H}_{2} \mathrm{O}$ revealed that for seabass fed a conventional high-protein/low-CHO diet, essentially all blood glucose and hepatic glycogen synthesis were derived via gluconeogenesis $^{(11,12)}$. We hypothesised that when dietary fishmeal is partially substituted by digestible (gelatinised) starch, the contribution of dietary $\mathrm{CHO}$ to blood glucose and hepatic glycogen appearance would significantly increase while gluconeogenic contribution would correspondingly be reduced. So far, data on enzymes' activity and/or mRNA abundance have largely elucidated the response of $\mathrm{CHO}$ metabolism in fish ${ }^{(2)}$. Therefore, we followed up the ${ }^{2} \mathrm{H}_{2} \mathrm{O}$ analysis with the expression of key enzymes directly or indirectly involved with the utilisation of dietary $\mathrm{CHO}$, in order to corroborate the hypothesised metabolic shift from a no-CHO to a high$\mathrm{CHO}$ diet.

\section{Materials and methods}

\section{Fish handling and sampling}

For the present study, European seabass (D. labrax L.) provided by Tinamenor (Cantabria, Spain) were transported to the laboratory and randomly assigned to two different tanks (thirty-two fish per tank; mean initial length $10 \cdot 8$ (SEM $0 \cdot 2) \mathrm{cm}$ and mean initial body weight 21.9 (SEM $0 \cdot 2$ ) g). Fish were acclimatised in 200-litre polyethylene circular tanks supplied with well-aerated filtered seawater from a recirculated system set to $20 \pm 1^{\circ} \mathrm{C}, 30 \pm 1 \%$ salinity and $\mathrm{O}_{2}$ levels above $80 \%$ saturation under natural photoperiod. These conditions were maintained throughout the experiment. All experimental procedures complied with the Guidelines of the European Union Council (86/609/EU). The fish were fed two experimental diets that were formulated by Sparos Lda. (Table 1): a control diet (CTRL) with no $\mathrm{CHO}$ (except for an inert filler of cellulose without any nutritional value to maintain pellet integrity in water), and an experimental diet containing 30\% digestible starch (DS; gelatinised pea starch). All diets were formulated to fulfil the nutritional requirements of the species. During this feeding period, fish were fed twice per $\mathrm{d}$ ad libitum $(6 \mathrm{~d} /$ week). Following this period, each group was transferred to a $5 \%{ }^{2} \mathrm{H}$-enriched seawater tank for $6 \mathrm{~d}$. This tank was maintained with an independent closed filtering system, but had similar characteristics to the tanks used during the feeding period in terms of size, volume of water (200litres), opacity, filtering material and water parameters. Seawater was enriched with ${ }^{2} \mathrm{H}_{2} \mathrm{O}$ with the addition of $99 \%$-enriched ${ }^{2} \mathrm{H}_{2} \mathrm{O}$ (Euriso-Top) as described previously by Viegas et al. ${ }^{(13)} .{ }^{2} \mathrm{H}$ enrichment was quantified throughout the experiment as described by Jones et al. ${ }^{(14)}$.
Table 1. Ingredients and proximate composition of the experimental diets provided to Dicentrarchus labrax

\begin{tabular}{lcc}
\hline Ingredients (\%) & CTRL diet & DS diet \\
\hline Fishmeal* $^{*}$ & 65.5 & 54.6 \\
Gelatinised pea starch† & 0.0 & 33.4 \\
Fish oilł & 9.8 & 10.5 \\
Vitamin and mineral premix§ & 1.0 & 1.0 \\
Binder (diatomaceous earth)\| & 0.5 & 0.5 \\
Cellulose (inert filler) & 23.2 & 0.0 \\
Proximate composition (\% dry weight) & & \\
DM & 96.0 & 95.6 \\
CP & 50.2 & 50.2 \\
CF & 16.1 & 16.1 \\
Starch & 0.2 & 17.8 \\
Ash & 11.5 & 9.3 \\
Gross energy (kJ/g dry weight) & 22.66 & 22.03 \\
\hline
\end{tabular}

CTRL, control; DS, digestible starch; CP, crude protein; CF, crude fat.

* Peruvian fishmeal LT: $67 \%$ CP, $9 \%$ CF, EXALMAR.

†Aquatex 8071 , gelatinised dehulled microground pea meal: $23 \% \mathrm{CP}, 50 \%$ starch, SOTEXPRO.

¥ Marine oil omega 3: Henry Lamotte Oils GmbH

$\S$ PVO40.01 premix for marine fish, PREMIX Lda. Vitamins (IU or $\mathrm{mg} / \mathrm{kg}$ diet): $\mathrm{DL}-\alpha$-tocopherol acetate, $100 \mathrm{mg}$; sodium menadione bisulphate, $25 \mathrm{mg}$; retinyl acetate, $20000 \mathrm{IU}$; DL-cholecalciferol, $2000 \mathrm{IU}$; thiamin, $30 \mathrm{mg}$; riboflavin, $30 \mathrm{mg}$; pyridoxine, $20 \mathrm{mg}$; $\mathrm{B}_{12}, 0.1 \mathrm{mg}$; nicotinic acid, $200 \mathrm{mg}$; folic acid, $15 \mathrm{mg}$; ascorbic acid, $1000 \mathrm{mg}$; inositol, $500 \mathrm{mg}$; biotin, $3 \mathrm{mg}$; calcium pantothenate, $100 \mathrm{mg}$; choline chloride, $1000 \mathrm{mg}$, betaine, $500 \mathrm{mg}$. Minerals (g or $\mathrm{mg} / \mathrm{kg}$ diet): cobalt sulphate, $2.5 \mathrm{mg}$; copper sulphate, $1.1 \mathrm{mg}$; ferric citrate, $0.2 \mathrm{~g}$; potassium iodide, $5 \mathrm{mg}$; manganese sulphate, $15 \mathrm{mg}$; sodium selenite, $0.2 \mathrm{mg}$; zinc sulphate, $40 \mathrm{mg}$; magnesium hydroxide, $0.6 \mathrm{~g}$; potassium chloride $1.1 \mathrm{~g} ; \mathrm{NaCl}, 0.5 \mathrm{~g}$; calcium carbonate, $4 \mathrm{~g}$.

\| Kielseguhr: LIGRANA GmbH.

If Microcrystalline cellulose, Blanver.

During the period in ${ }^{2} \mathrm{H}$-enriched seawater, fish were fed once per $\mathrm{d}$ (ad libitum) and killed $24 \mathrm{~h}$ after the last meal on day 5. Fish were anaesthetised in a 30-litre tank of $5 \%{ }^{2} \mathrm{H}$-enriched seawater containing $0 \cdot 1 \mathrm{~g} / \mathrm{l}$ of MS-222. Fish were measured and weighed, and blood was drawn from the caudal vein with heparinised syringes. Fish were then killed by cervical section. Liver was excised, weighed, freeze-clamped in liquid $\mathrm{N}_{2}$ and stored at $-80^{\circ} \mathrm{C}$ until further analysis.

\section{Metabolite preparation}

Immediately after blood withdrawal, a $100 \mu \mathrm{l}$ aliquot was kept on ice. After centrifugation $(3000 \mathrm{~g}, 10 \mathrm{~min})$, plasma samples were stored at $-20^{\circ} \mathrm{C}$ for ${ }^{2} \mathrm{H}$ enrichments and glucose and TAG quantification with commercial kits ( $n$ 8, Cromatest ${ }^{\circledR}$; Linear Chemicals). To obtain sufficient amounts of analytes for generating ${ }^{2} \mathrm{H}$ NMR spectra of blood glucose derivatives with a high signal:noise ratio, each sample consisted of blood from three to seven fish (pooled analyses: $n 6$ per diet). Blood was deproteinised by the addition of $0.3 \mathrm{M}$ $\mathrm{ZnSO}_{4}$ and $0.15 \mathrm{M}-\mathrm{Ba}(\mathrm{OH})_{2}(1.5 \mathrm{ml}$ of each solution per $\mathrm{ml}$ blood), followed by centrifugation at $3500 \mathrm{~g}$ for $15 \mathrm{~min}$. The supernatant was desalted by passage through sequential columns containing Dowex ${ }^{\circledR} \quad 50 \mathrm{WX} 8$ (hydrogen form; Sigma-Aldrich) and Amberlite ${ }^{\circledR}$ IRA-67 (free base, Fluka; Sigma-Aldrich), and lyophilised.

Pulverised liver tissue was used for enzyme assays $(n 7)$, mRNA extraction ( $n$ 6), glycogen quantification ( $n$ 6), as described by Keppler \& Decker ${ }^{(15)}$. Liver samples from three to seven fish under each condition were pooled for glycogen 
Table 2. Primer pairs used for the partial complementary DNA amplification of glutamate dehydrogenase (GDH) by RT-PCR and expected band extension*

\begin{tabular}{|c|c|c|c|c|c|}
\hline \multirow[b]{2}{*}{ Genes } & & RT-PCR & \multirow[b]{2}{*}{$\begin{array}{l}\text { Expected band } \\
\text { extension (bp) }\end{array}$} & Quantitative real-time RT-PCR & \multirow[b]{2}{*}{$\begin{array}{c}\text { GenBank } \\
\text { accession no }\end{array}$} \\
\hline & & Primer sequence $\left(5^{\prime}-3^{\prime}\right)$ & & Primer sequence $\left(5^{\prime}-3^{\prime}\right)$ & \\
\hline \multicolumn{6}{|c|}{ Housekeeping gene } \\
\hline $18 S$ & $\begin{array}{l}\text { Forward } \\
\text { Reverse }\end{array}$ & & & $\begin{array}{l}\text { ACGGACGAAAGCGAAAGCA } \\
\text { GGAACTACGACGGTATCTGATC }\end{array}$ & AM419038 \\
\hline \multicolumn{6}{|c|}{ Amino acid metabolism } \\
\hline$c A L T$ & $\begin{array}{l}\text { Forward } \\
\text { Reverse }\end{array}$ & & & $\begin{array}{l}\text { TGAAGGAGGGGGTCAAGAAA } \\
\text { AGGGTAAGAACACAGAGCCA }\end{array}$ & JX073702 \\
\hline$G D H$ & $\begin{array}{l}\text { Forward } \\
\text { Reverse }\end{array}$ & $\begin{array}{l}\text { CAATGCCCATGCCTGTGTGACGG } \\
\text { GGTGGTAGTTGGAGTCCCTCT }\end{array}$ & 606 & $\begin{array}{l}\text { CCATCAGCCAGGGAGGAATC } \\
\text { TGCTCATGTAAGACGCCTCG }\end{array}$ & KF857576 \\
\hline \multicolumn{6}{|c|}{ Gluconeogenesis } \\
\hline G6Pase & $\begin{array}{l}\text { Forward } \\
\text { Reverse }\end{array}$ & & & $\begin{array}{l}\text { CCTGTGGATGCTAATGGGTC } \\
\text { TGACCTGATGTGGGAAGTGG }\end{array}$ & JX073707 \\
\hline \multicolumn{6}{|l|}{ Glycolysis } \\
\hline GK & $\begin{array}{l}\text { Forward } \\
\text { Reverse }\end{array}$ & & & $\begin{array}{l}\text { GAATGACACAGTAGCCACCA } \\
\text { CACAGTCCTCATCTCCTC }\end{array}$ & JX073704 \\
\hline
\end{tabular}

$c A L T$, cytosolic alanine aminotransferase; G6Pase, glucose 6-phosphatase; GK, glucokinase.

${ }^{*}$ Primer pairs were used to assess the mRNA levels of $c A L T, G D H$, G6Pase and GK by quantitative real-time RT-PCR analysis, and respective GenBank accession numbers.

extraction (pooled analyses: $n 5$ for the CTRL diet and $n 6$ for the DS diet). Hepatic glycogen was extracted by precipitation with $70 \%$ ethanol followed by alkaline tissue hydrolysis, as described by Viegas et al. ${ }^{(12)}$. To hydrolyse glycogen to glucose, glycogen was resuspended in $5 \mathrm{ml}$ sodium acetate buffer ( $0.05 \mathrm{M}, \mathrm{pH} 4.5)$, and $20 \mu \mathrm{l}$ of an aqueous solution containing sixteen units of amyloglucosidase from Aspergillus niger (glucose-free preparation; Sigma-Aldrich) were added. The samples were incubated overnight at $55^{\circ} \mathrm{C}$ and centrifuged at $3500 \mathrm{~g}$ for $10 \mathrm{~min}$. The supernatant was collected and lyophilised. To optimise signal resolution in the ${ }^{2} \mathrm{H}$ NMR spectra, both blood glucose and glucosyl units hydrolysed from hepatic glycogen were converted into monoacetone glucose, as described previously ${ }^{(13)}$.

\section{Enzyme activity and mRNA expression levels}

Several key enzymes were analysed due to their relevance in the metabolic network. Enzyme activity assays were carried out as described previously: glucokinase (GK, EC 2.7.1.2) ${ }^{(16)}$; glucose 6-phosphatase (G6Pase, EC 3.1.3.9) ${ }^{(17)}$; pyruvate kinase (EC 2.7.1.40), 6-phosphofructo 1-kinase (PFK-1; EC 2.7.1.11), fructose-1,6-bisphosphatase (FBPase; $E C$ 3.1.3.11) ${ }^{(18)}$; glutamate dehydrogenase (GDH; EC 1.4.1.2) ${ }^{(19)}$. Alanine aminotransferase (cytosolic) (EC 2.6.1.2) was determined using a commercial kit (Cromatest; Linear Chemicals). All enzyme activity assays were carried out at $30^{\circ} \mathrm{C}$ and followed at $340 \mathrm{~nm}$. Total protein content of the liver crude extracts was determined by the Bradford method (Bio-Rad) at $30^{\circ} \mathrm{C}$ using bovine serum albumin as a standard and followed at $600 \mathrm{~nm}$. All assays for metabolites, enzyme activities and total protein were adapted for automated measurements using a Cobas Mira S spectrophotometric analyser (HoffmanLa Roche). Enzyme activities are expressed per mg of soluble protein (specific activity). One unit of enzyme activity was defined as the amount of enzyme necessary to transform $1 \mu \mathrm{mol}$ of substrate per min. Total RNA extraction, reverse transcription, amplification by RT-PCR, RT-PCR product analysis and purification, transformation in competent cells, sequencing and design of specific oligonucleotides for quantitative real-time RT-PCR were conducted, as described previously, for GK and G6Pase ${ }^{(11)}$, and cytosolic alanine aminotransferase ${ }^{(20)}$. To our knowledge, no sequence was available for GDH, so for its partial sequencing, we followed the procedure described by Viegas and colleagues ${ }^{(11,20)}$. Amplification of GDH by RT-PCR was carried out using the pairs of primers designed from highly conserved regions of nucleotide sequences published in the GenBank for other fish species (Table 2). Quantitative real-time RT-PCR were carried out in a StepOnePlus ${ }^{\mathrm{TM}}$ Real-Time PCR System (Applied Biosystems ${ }^{\circledR}$ ) using the pairs of oligonucleotides listed in Table 2. Variations in mRNA abundance and $n$-fold changes were calculated relative to the CTRL fish using the standard $\Delta \Delta C_{\mathrm{t}}$ method adjusted for PCR efficiency as proposed by Pfaffl ${ }^{(21)}$.

\section{${ }^{2} H$ NMR analysis}

Plasma water with ${ }^{2} \mathrm{H}$ enrichments were determined from $10 \mu \mathrm{l}$ aliquots of plasma by ${ }^{2} \mathrm{H}$ NMR, as described by Jones et $a{ }^{(14)}$. Plasma water was assumed to be $92 \%$ of total plasma ${ }^{(22)}$. Proton-decoupled ${ }^{2} \mathrm{H}$ NMR spectra of monoacetone glucose samples were obtained as described previously for blood glucose ${ }^{(11)}$ and liver glycogen ${ }^{(12)}$ using a Varian VNMRS $600 \mathrm{MHz}$ NMR (Agilent) spectrometer. Spectra were analysed with the NUTS PC-based NMR spectral analysis software (Acorn NMR Inc.).

\section{Quantification of blood glucose and hepatic glycogen sources}

Sources of blood glucose were quantified from the ${ }^{2} \mathrm{H}$ enrichment levels of blood glucose and plasma water (PW) as described previously ${ }^{(11)} \cdot{ }^{2} \mathrm{H}$ enrichment levels of the two groups were normalised in order to directly compare the 
ratios of glucose and glycogen ${ }^{2} \mathrm{H}$ enrichment levels relative to PW. It was assumed that the blood glucose pool had completely turned over during the $6 \mathrm{~d}$ period in ${ }^{2} \mathrm{H}$-enriched seawater. Contributions from glucose 6-phosphate (G6P) were calculated as follows:

Fraction from endogenous G6P sources $=100 \times \mathrm{H} 2 / \mathrm{PW}$,

Fraction from dietary sources

$$
=100-\text { endogenous G6P sources. }
$$

Endogenous sources of glucose were resolved into gluconeogenic and non-gluconeogenic fractions based on the enrichment of positions 5 and 2. Under the feeding conditions, the fractional non-gluconeogenic contribution included G6P derived via glycogen phosphorylase as well as G6P synthesised by the futile cycling of glucose via GK and G6Pase:

Gluconeogenic-contribution $=100 \times \mathrm{H} 5 / \mathrm{H} 2$,

$$
\begin{aligned}
& \text { Non - gluconeogenic contribution } \\
& =100-\text { gluconeogenic contribution. }
\end{aligned}
$$

Sources of hepatic glycogen synthesis were quantified from the ${ }^{2} \mathrm{H}$ enrichment levels of hepatic glycogen and PW, as described previously ${ }^{(12)}$ :

Fraction from endogenous G6P $(\%)=100 \times \mathrm{H} 2 / \mathrm{PW}$,

Fraction of unlabelled glycogen $(\%)$

$$
=100-\text { fraction from endogenous G6P. }
$$

Unlike blood glucose, hepatic glycogen was only partially turned over during the $6 \mathrm{~d}$ period in ${ }^{2} \mathrm{H}$-enriched seawater. Thus, the unlabelled fraction consisted of pre-existing glycogen, whose provenance (i.e. synthesised via direct or indirect pathways) was unknown. From the labelled endogenous G6P, the contributions of direct and indirect pathways to glycogenic G6P flux were estimated from the ratio of glycogen position 5 and 2 enrichments:

Indirect pathway contribution $(\%)=100 \times \mathrm{H} 5 / \mathrm{H} 2$,

$$
\begin{aligned}
& \text { Direct pathway contribution }(\%) \\
& =100-\text { indirect pathway contribution. }
\end{aligned}
$$

Under the feeding conditions, hepatic glycogen levels were assumed to be constant over the $6 \mathrm{~d}$ period when the fish were in ${ }^{2} \mathrm{H}$-enriched water. Therefore, the fractional replacement rate was calculated from the fraction of endogenous G6P (equation 5) per $\mathrm{h}$. The fractional replacement rate can be converted to the mean absolute rate by multiplying it by the mean hepatic glycogen level, expressed as $\mu \mathrm{mol} / \mathrm{kg}$ fish. Indirect and direct pathway fluxes can be discriminated by multiplying the absolute replacement rates for equations 7 and 8 , respectively.

\section{Statistical analysis}

Student's two-tailed unpaired $t$ test was used to compare means between the CTRL and DS diets for several parameters. Analyses were performed in GraphPad Prism ${ }^{\circledR} 6$ software (GraphPad Software, Inc.), and differences were considered statistically significant at $P<0.05$.

\section{Results \\ Growth rates and plasma metabolite levels}

Biochemical parameters and growth performance in fish fed with a no-CHO (CTRL) and a high-CHO (DS) diet are summarised in Table 3. Blood glucose values were not significantly different. Hepatic glycogen levels were significantly higher in the DS fish than in the CTRL fish, although the hepatosomatic index did not reflect such difference. Growth performance was not affected by diet composition as similar daily growth indices were observed.

\section{Plasma water and metabolite enrichments from ${ }^{2} \mathrm{H}_{2} \mathrm{O}$}

PW enrichment for the CTRL and DS fish was $5 \cdot 0$ (SEM 0.2)\%, which was consistent with the ${ }^{2} \mathrm{H}$-enriched tank water. Moreover, during the $6 \mathrm{~d}$ period, tank water ${ }^{2} \mathrm{H}$ enrichments did not change significantly (data not shown). Since fish PW and tank water enrichments became equivalent within less than $6 h^{(13)}$, the PW enrichment level measured at the end of the study was considered to reflect that of a constant ${ }^{2} \mathrm{H}$-precursor enrichment level over the preceding $6 \mathrm{~d}$. As a result, synthesis and/or cycling from G6P and gluconeogenic precursors led to the incorporation of ${ }^{2} \mathrm{H}$ into specific positions of both blood glucose ${ }^{(13)}$ and hepatic glycogen ${ }^{(12)}$. Figure 1 shows the representative ${ }^{2} \mathrm{H}$ NMR spectra of monoacetone glucose derived from glucose and glycogen obtained from fish fed the CTRL and DS diets. The positional ${ }^{2} \mathrm{H}$ enrichment levels estimated from the analysis of their respective ${ }^{2} \mathrm{H}$ NMR signals are listed in Table 4 . The high signal:noise ratio of ${ }^{2} \mathrm{H}$ resonances allowed precise quantification of all carbon positional ${ }^{2} \mathrm{H}$ enrichments, where equivalent intensities indicate equivalent enrichment for a certain position. Glucose enrichment in position 2 calculated from the spectra approached that of PW, confirming that the blood glucose pool fully turned over during the $6 \mathrm{~d}$ period in ${ }^{2} \mathrm{H}$-enriched seawater for the

Table 3. Biochemical parameters and growth performance in seabass (Dicentrarchus labrax) fed with a no-carbohydrate diet as the control (CTRL) and a $30 \%$ digestible starch (DS) diet

(Mean values with their pooled standard errors)

\begin{tabular}{lccc}
\hline & CTRL diet & DS diet & Pooled SEM \\
\hline Plasma glucose $(\mathrm{mm})$ & 10.0 & 8.2 & 0.7 \\
Liver glycogen $(\mathrm{g} / 100 \mathrm{~g})$ & 9.9 & $11.6^{*}$ & 0.4 \\
DGI† & 0.79 & 0.80 & 0.02 \\
HSI & 1.6 & 1.5 & 0.03
\end{tabular}

DGI, daily growth index; HSI, hepatosomatic index.

${ }^{\star}$ Mean value was significantly different from that of the CTRL diet $(P<0.05 ; t$ test $)$ †DGI $=100 \times\left(\right.$ final body weight ${ }^{1 / 3}-$ initial body weight $\left.^{1 / 3}\right) / \mathrm{d}$.

$\ddagger \mathrm{HSI}=100$ (liver weight/body weight). 
(a)

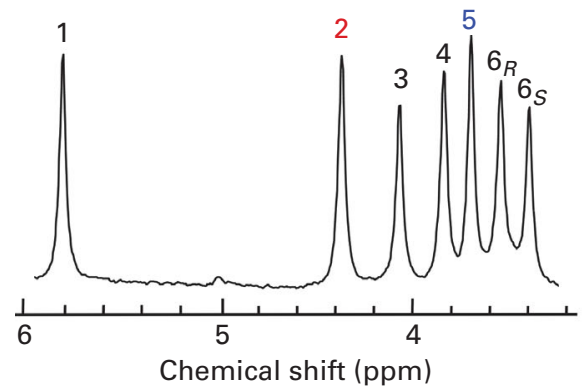

(c)

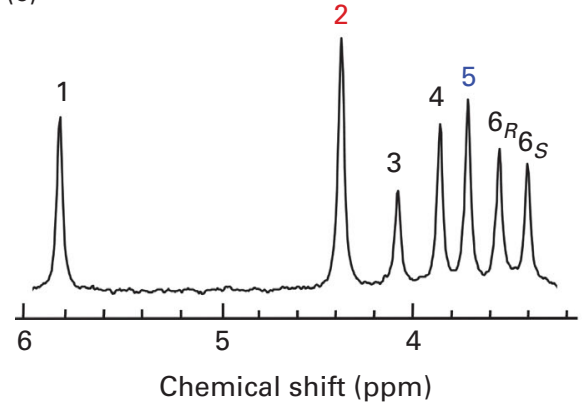

(b)

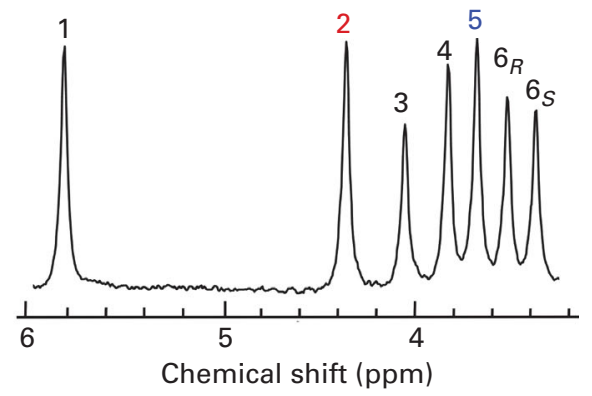

(d)

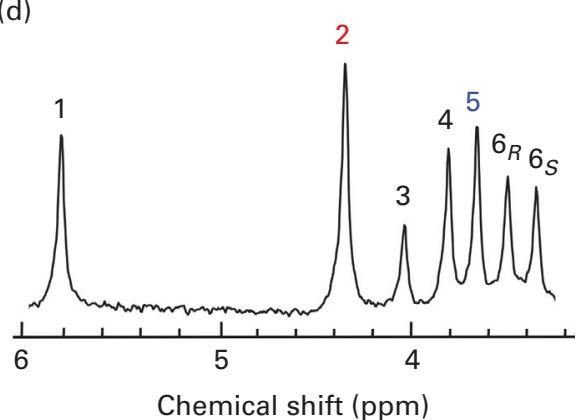

Fig. 1. Representative ${ }^{2} \mathrm{H}$ NMR spectra of monoacetone glucose samples derived from (a, c) hepatic glycogen and (b, d) blood glucose of seabass (Dicentrarchus labrax) fed with (a, b) a no-carbohydrate diet as the control and (c, d) a $30 \%$ digestible starch diet, and sampled after a $6 \mathrm{~d}$ residence in a tank with $5 \%{ }^{2} \mathrm{H}$ enriched water. The numbers above each signal represents its position within the original glucose molecule. The signals at positions 2 and 5 for each spectrum are highlighted (in red and blue, respectively). (A colour version of this figure can be found online at http://www.journals.cambridge.org/bjn).

CTRL and DS fish. In contrast, the hepatic glycogen turnover rate was slow for both diets as revealed by glycogen position 2 enrichment, which was lower than PW. The CTRL fish turned over about one-half and the DS fish turned over onethird of their hepatic glycogen pool during the $6 \mathrm{~d}$ period in ${ }^{2} \mathrm{H}$-enriched seawater, reflecting a relatively static hepatic glycogen pool under the daily feeding regimen. Except for position 2, the ${ }^{2} \mathrm{H}$ enrichment distribution of blood glucose showed significant differences between the CTRL and DS fish. While the enrichment of position 2 approached that of PW for both the CTRL and DS conditions, the enrichment of position 5 was significantly lower for fish fed with the DS diet. From the enrichment distribution (Table 4), the fractional sources of blood glucose were calculated, and data are shown in Fig. 2. The results reveal a significant shift from gluconeogenesis towards contributions of unlabelled glucose that had undergone futile cycling via hepatic G6P. This cycled glucose was presumably originated from digested dietary starch. In the DS fish, the fraction of blood glucose derived directly by absorption (therefore unlabelled in any position by ${ }^{2} \mathrm{H}$ ) almost doubled compared with the CTRL fish, accounting for approximately $20 \%$ of blood glucose appearance. Contributions

Table 4. Blood glucose and hepatic glycogen positional ${ }^{2} \mathrm{H}$ enrichments $\ddagger$ and plasma water $(\mathrm{PW}){ }^{2} \mathrm{H}$ enrichment as quantified by ${ }^{2} \mathrm{H}$ NMR in seabass (Dicentrarchus labrax) fed with a no-carbohydrate diet as the control (CTRL) and a $30 \%$ digestible starch (DS) diet and sampled after a 6 -d residence in a tank with $5 \%{ }^{2} \mathrm{H}$-enriched water (Mean values with their standard errors)

\begin{tabular}{|c|c|c|c|c|c|c|c|c|c|}
\hline \multirow[b]{2}{*}{ Metabolites } & \multirow[b]{2}{*}{ Diet } & \multicolumn{7}{|c|}{ Glucose and glycogen positional ${ }^{2} \mathrm{H}$ enrichments } & \multirow[b]{2}{*}{ PW } \\
\hline & & 1 & 2 & 3 & 4 & 5 & $6_{R}$ & $6 s$ & \\
\hline \multirow[t]{4}{*}{ Glucose } & CTRL (n 6) & $4 \cdot 2$ & $4 \cdot 6$ & $3 \cdot 1$ & $4 \cdot 0$ & 4.4 & $3 \cdot 4$ & 2.9 & $5 \cdot 0$ \\
\hline & $\mathrm{DS}(n 6)$ & & & & & & & & \\
\hline & Mean & $2 \cdot 9^{\star \star \star}$ & $4 \cdot 2$ & $0 \cdot 7^{\star \star \star}$ & $2 \cdot 5^{\star \star \star}$ & $2 \cdot 8^{\star \star \star} \dagger$ & $2 \cdot 1^{\star \star \star}$ & $1 \cdot 9^{* * \star}$ & $5 \cdot 0$ \\
\hline & Pooled SEM & $0 \cdot 2$ & $0 \cdot 1$ & 0.4 & $0 \cdot 2$ & 0.3 & 0.2 & $0 \cdot 2$ & 0.2 \\
\hline \multirow[t]{6}{*}{ Glycogen } & CTRL $(n 5)$ & & & & & & & & \\
\hline & Mean & $2 \cdot 0$ & 2.4 & $2 \cdot 0$ & $2 \cdot 3$ & $2 \cdot 5$ & $2 \cdot 3$ & 1.9 & $5 \cdot 0$ \\
\hline & SEM & 0.2 & 0.1 & $0 \cdot 1$ & 0.1 & $0 \cdot 1$ & 0.1 & 0.1 & 0.2 \\
\hline & $\mathrm{DS}(n 6)$ & & & & & & & & \\
\hline & Mean & $1 \cdot 0^{* *}$ & $1 \cdot 8^{\star *}$ & $0 \cdot 8^{\star \star \star}$ & $1 \cdot 2^{\star \star \star}$ & $1 \cdot 3^{\star \star *} \dagger$ & $1 \cdot 0^{\star \star \star}$ & $0 \cdot 9^{\star \star \star}$ & $5 \cdot 0$ \\
\hline & SEM & 0.1 & 0.1 & $0 \cdot 1$ & $0 \cdot 1$ & 0.1 & 0.1 & $0 \cdot 1$ & 0.2 \\
\hline
\end{tabular}

Mean value was significantly different from that of the CTRL group: ${ }^{\star \star} P<0.01,{ }^{\star \star \star} P<0.001$ ( $t$ test).

† Mean value was significantly different from that at position $2(P<0.05 ; t$ test). Note that means were tested only between the positions of interest (2 and 5 ).

$\ddagger$ Enrichments adjusted for tank water at $5.0 \%{ }^{2} \mathrm{H}_{2} \mathrm{O}$ 


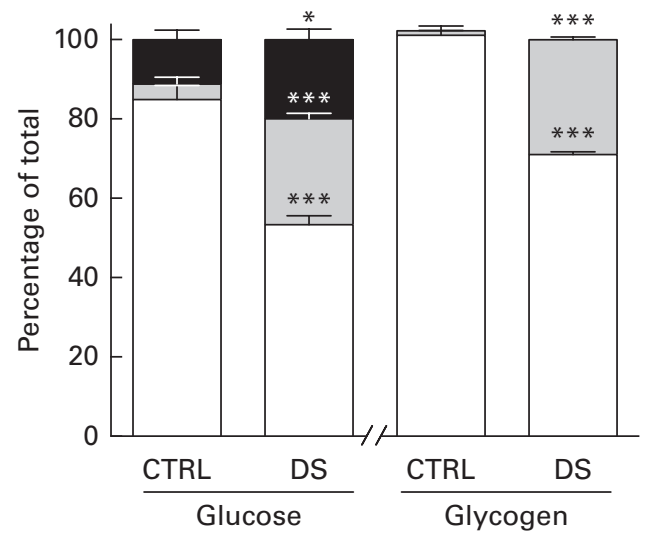

Fig. 2. Sources of blood glucose and hepatic glycogen for seabass (Dicentrarchus labrax) fed with a control (CTRL) diet containing no carbohydrate and with a diet containing $30 \%$ digestible starch (DS). Contributions are represented as percentage of total (\%) and are resolved into unlabelled (dietary absorption, $\mathbf{\square}$ ), non-gluconeogenic glucose 6-phosphate (G6P; direct pathway in glycogen, $\square$ ) and gluconeogenic G6P (indirect pathway in glycogen, $\square$ ). Values are means, with their standard errors represented by vertical bars. Mean value was significantly different from that of the CTRL diet: ${ }^{*} P<0.05,{ }^{* *} P<0.001$ ( $t$ test).

from absorbed glucose that had undergone futile cycling also increased significantly compared with the CTRL fish, accounting for $27 \%$ of blood glucose appearance. Thus, $24 \mathrm{~h}$ after the last meal, almost half of the circulating glucose was derived from dietary $\mathrm{CHO}$ in the DS fish $(20 \%$ unlabelled $+27 \%$ non-gluconeogenic), while gluconeogenesis accounted for $85 \%$ of circulating glucose in the CTRL fish. For hepatic glycogen, the CTRL fish exhibited equivalent ${ }^{2} \mathrm{H}$ enrichments of positions 2 and 5. This is consistent with a substantial contribution of the indirect pathway to glycogen synthesis flux (Tables 4 and 5). For the DS fish, there was a significant direct pathway contribution to glycogen synthesis, indicating the recruitment of dietary glucose for glycogenesis. Meanwhile, indirect pathway fluxes were significantly smaller, consistent with a sparing of gluconeogenic carbon flow for hepatic glycogen synthesis.

\section{Enzyme activity and mRNA expression levels}

To determine whether hepatic nutrient fluxes were associated with changes in the mobilisation of amino acids and glucose, activity and/or expression levels of enzymes involved in amino acid and $\mathrm{CHO}$ metabolism were determined (Fig. 3).
Liver transaminase activity (alanine aminotransferase) was similar in fish subjected to both diets, while GDH activity was significantly higher in the DS fish than in the CTRL fish. A 603 bp complementary DNA sequence encoding GDH was isolated and cloned from the liver of D. labrax. This fragment was approximately $90 \%$ identical to Monopterus albus (GenBank accession no. JF694445) and approximately $85 \%$ identical to Salmo salar (AJ532825) and Oncorbynchus mykiss (AF427344). The mRNA expression levels of GDH showed no statistical differences. The activity of hepatic enzymes responsible for the uptake and disposal of glucose, GK and G6Pase, respectively, did not show any modulation resulting from increased $\mathrm{CHO}$ ingestion. However, mRNA expression levels of $G K$ were significantly increased in the DS fish. In contrast to the observations on GK $v$. G6Pase activity, increased $\mathrm{CHO}$ ingestion resulted in an expected reciprocation between PFK-1 $v$. FBPase activities. The DS fish exhibited an increase in PFK-1 activity, but a decrease in FBPase activity.

\section{Discussion}

\section{Hepatic enzyme regulation from increased carbohydrate} ingestion

In regularly fed fish, changes in transaminase activity are mainly caused by dietary protein, but not dietary CHO. This is thought to reflect the use of excess carbon backbones from amino acids to supply energy demands ${ }^{(23-26)}$. However, in agreement with the present study, modifying the amount and type of $\mathrm{CHO}$ under constant dietary protein levels did not cause any significant alteration in alanine aminotransferase activity, as has been already observed in seabass ${ }^{(9)}$. GDH activity, quantified in the direction of glutamate production, increased with ingestion of dietary CHO. It is known that this enzyme plays a role in directing glutamate carbon entry into the Krebs cycle. However, GDH activity is highly influenced by the cellular energy state, being activated when the mitochondrial energetic status is poor ${ }^{(27)}$. We speculate that elevated hepatic GDH activity may reflect a suboptimal hepatocellular energy status, possibly reflecting a limited adaptation of these carnivorous fish towards energy generation from $\mathrm{CHO}$-rich diets.

Feeds with high protein: $\mathrm{CHO}$ ratios, that mimic the seabass natural diet, result in residual mRNA and activity levels for hepatic GK. Stimulation of $G K$ expression by dietary $\mathrm{CHO}$

Table 5. Hepatic glycogen synthesis fluxes in seabass (Dicentrarchus labrax) fed daily with a no-carbohydrate diet as the control (CTRL) and a $30 \%$ digestible starch (DS) diet and sampled after a 6-d residence in a tank with $5 \%{ }^{2} \mathrm{H}$-enriched water (Mean values with their standard errors)

\begin{tabular}{|c|c|c|c|c|c|c|c|c|c|c|}
\hline \multirow[b]{2}{*}{ Diet } & \multicolumn{2}{|c|}{$\begin{array}{l}\text { Hepatic glycogen } \\
\text { (mmol/kg fish) }\end{array}$} & \multicolumn{2}{|c|}{$\begin{array}{l}\text { Fractional } \\
\text { replacement rate } \\
(\% \text { per } h)\end{array}$} & \multicolumn{2}{|c|}{$\begin{array}{c}\text { Absolute } \\
\text { replacement rate } \\
(\mu \mathrm{mol} / \mathrm{kg} \text { per } \mathrm{h})\end{array}$} & \multicolumn{2}{|c|}{$\begin{array}{l}\text { Direct pathway flux } \\
(\mu \mathrm{mol} / \mathrm{kg} \text { per } \mathrm{h})\end{array}$} & \multicolumn{2}{|c|}{$\begin{array}{c}\text { Indirect pathway } \\
\text { flux }(\mu \mathrm{mol} / \mathrm{kg} \text { per } \mathrm{h})\end{array}$} \\
\hline & Mean & SEM & Mean & SEM & Mean & SEM & Mean & SEM & Mean & SEM \\
\hline CTRL ( $n 5)$ & 8.553 & 0.286 & 0.33 & 0.03 & 28.02 & 0.97 & -0.35 & 0.35 & $28 \cdot 37$ & 1.27 \\
\hline $\mathrm{DS}(n 6)$ & $9 \cdot 747$ & 0.525 & $0 \cdot 24^{\star \star}$ & 0.04 & $23 \cdot 21^{*}$ & 1.60 & $6 \cdot 67^{\star \star \star}$ & 0.49 & $16 \cdot 54^{\star \star \star}$ & $1 \cdot 15$ \\
\hline
\end{tabular}

Mean value was significantly different from that of the CTRL diet: ${ }^{\star} P<0.05,{ }^{\star \star} P<0.01,{ }^{\star \star \star} P<0.001$ ( $t$ test). 

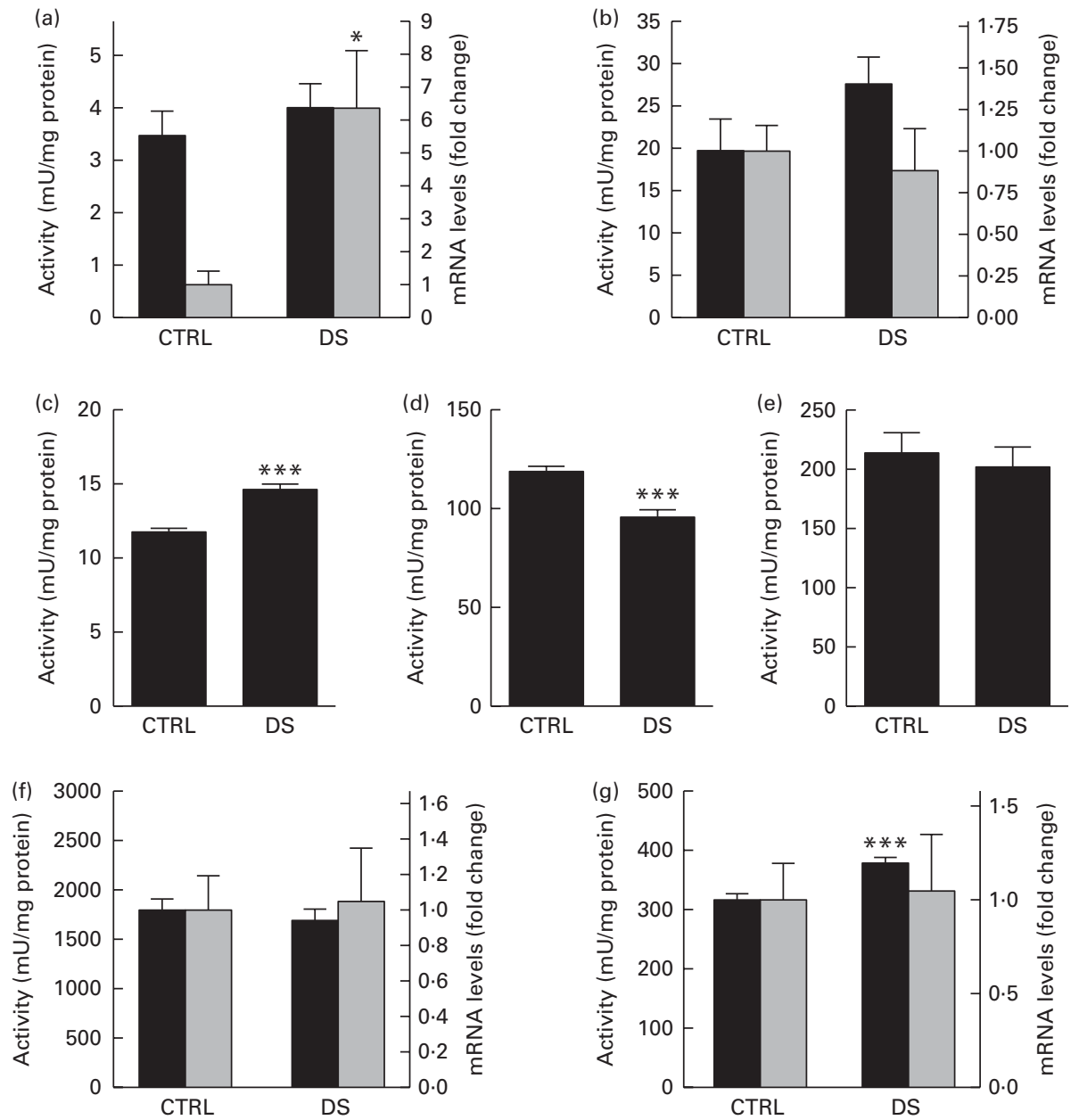

Fig. 3. Specific activity $(\square)$ and mRNA abundance $(\square)$ for amino acid metabolism, glycolysis and gluconeogenesis enzymes in the liver of seabass (Dicentrarchus labrax) fed with a no-carbohydrate diet as the control (CTRL) and a $30 \%$ digestible starch (DS) diet: (a) glucokinase; (b) glucose 6-phosphatase; (c) 6-phosphofructo 1-kinase; (d) fructose-1,6-bisphosphatase; (e) pyruvate kinase; (f) cytosolic alanine aminotransferase; (g) glutamate dehydrogenase. Activity is expressed as $\mathrm{mU} / \mathrm{mg}$ protein and mRNA abundance as fold change with respect to the CTRL fish. mRNA abundances were normalised with mRNA abundance from ribosomal subunit 18 of $D$. labrax. Values are means, with their standard errors represented by vertical bars $(n 6)$. Mean value was significantly different from that of the CTRL diet: ${ }^{\star} P<0.05,{ }^{\star \star \star} P<0.001$ ( $t$ test).

has been reported in several fish species ${ }^{(17,28-32)}$ as that observed in the DS fish. However, GK activity seems to be differently influenced by dietary $\mathrm{CHO}$ depending on the species, $\mathrm{CHO}$ level and time of sampling after feeding. Postprandial GK activity is relatively dynamic, with maximal activities reaching after $6-8 \mathrm{~h}$ post-feeding ${ }^{(16,30,33-35)}$. In most studies where sampling was performed during peak response, GK activity has been found to be highly induced by dietary $\mathrm{CHO}$ in species such as rainbow trout $(\text { O. mykiss })^{(30,33,36)}$, gilthead seabream ${ }^{(17,23,28,30,37)}$ or common dentex (Dentex dentex $)^{(26)}$. However, other studies with gilthead seabream ${ }^{(38)}$ and seabass ${ }^{(7,9)}$ have reported otherwise. This raises doubts regarding the responsiveness of this enzyme's activity to a high-CHO diet, at least in these species. In studies where sampling was performed $20-24 \mathrm{~h}$ after the meal, where transition from the post-absorptive to the basal metabolic state takes place, enhanced GK activity has been found in rainbow trout $^{(30)}$ and gilthead seabream ${ }^{(29,39)}$. Studies with Senegalese sole (Solea senegalensis) ${ }^{(40)}$, blackspot seabream (Pagellus bogaraveo $)^{(41)}$, common carp (Cyprinus carpio) and gilthead seabream ${ }^{(30)}$ have reported no such differences and better align with our findings. While GK is responsive to increased dietary $\mathrm{CHO}$, glycaemic control in this setting also requires a reciprocal suppression of G6Pase activity. However, we did not observe significant changes in either G6Pase activity or mRNA abundance by dietary CHO. Moreover, no differences in glycaemia were observed between conditions as previously reported for seabass ${ }^{(7,9,42)}$. Studies with gilthead seabream $^{(28,37,43)}$ as well as seabass ${ }^{(6,7,9)}$ have also reported no effect of dietary $\mathrm{CHO}$ on G6Pase activity, $6 \mathrm{~h}$ after the last meal. Other similar reports have even revealed an increase in G6Pase activity in seabass ${ }^{(28)}$ and increased activity and mRNA abundance in rainbow trout ${ }^{(33)}$ with increasing dietary $\mathrm{CHO}$ ingestion. Similar to our observations, no alterations in G6Pase mRNA were induced $24 \mathrm{~h}$ after the last meal by dietary $\mathrm{CHO}$ in rainbow trout ${ }^{(32,43)}$, gilthead seabream and common carp $^{(29,44)}$. The lack of G6Pase suppression by $\mathrm{CHO}$ has been suggested as contributing to the inability of carnivorous fish to control glycaemia when fed with $\mathrm{CHO}$-enriched diets. It also explains the high rates of futile glucose-G6P cycling 
observed under feeding conditions since both GK and G6Pase are active at the same time ${ }^{(13,32,45)}$. Metabolic fluxes obtained from ${ }^{2} \mathrm{H}$ NMR in the present study and other studies ${ }^{(46)}$ associated with the lack of response observed in pyruvate kinase (present study), and PFK-1 ${ }^{(45,47)}$, located downstream of G6P in the glycolytic pathway, seem to support this assumption. Along with this futile cycling of glucose, the contribution of glycogen conversion to glucose via glycosidases (EC 3.2.1, includes glucosidases, amylases and glycogen-debranching enzymes) is yet to be evaluated. These alternative glucoseproducing pathways do not involve in the exchange of glucose and water hydrogens generating unlabelled glucose in the presence of ${ }^{2} \mathrm{H}_{2} \mathrm{O}^{(11)}$. Therefore, the present methodology is unable to estimate their roles in glucose fluxes.

The interconversion between fructose 6-phosphate and fructose 1,6-bisphosphate by the PFK-1/FBPase substrate cycle is another important regulatory locus for glucose metabolism, and unlike GK $v$. G6Pase, reciprocal changes in their activities between the CTRL and DS feeding conditions were observed. These findings were consistent with the expected shift towards glycolysis over gluconeogenesis in response to the more abundant dietary $\mathrm{CHO}$ for the DS fish as has previously been observed elsewhere for activity ${ }^{(29,33,48)}$ and mRNA abundance ${ }^{(32,34,44)}$.

\section{Analysis and comparison of ${ }^{2} \mathrm{H}_{2} \mathrm{O}$ with other tracer studies}

While enzyme activity and expression show robust responses to dietary $\mathrm{CHO}$ supplementation, supported by an extensive body of literature, how these translate to alterations in nutrient fluxes remains poorly understood. Recently, elegant analyses based on dietary ${ }^{13} \mathrm{C}$-enriched $\operatorname{starch}^{(49,50)}$, ${ }^{13} \mathrm{C}$-enriched protein ${ }^{(51)}$ and ${ }^{15} \mathrm{~N}$-enriched protein ${ }^{(50,52)}$ precursors coupled with mass spectrometric analysis of different tissues allowed carbon and nitrogen assimilation to be followed into protein, glycogen and lipids.

As observed in the present study, hepatic glycogen increases consistently with dietary $\mathrm{CHO}$ as reported previously $^{(7,9,23,42,53)}$. In the study of Felip et al. ${ }^{(52)}$ with gilthead seabream fed with a single meal of ${ }^{13} \mathrm{C}$-enriched starch, hepatic glycogen enrichment from ${ }^{13} \mathrm{C}$-enriched starch was presumed to occur mainly via the direct pathway, hence the fact that ${ }^{13} \mathrm{C}$ enrichment was maximal at $6 \mathrm{~h}$ suggests that direct pathway activity was most active at this time ${ }^{(52)}$. The depletion of glycogen ${ }^{13} \mathrm{C}$ enrichment between 6 and $24 \mathrm{~h}$ in the face of static hepatic glycogen levels may be explained by a switch from the direct to the indirect pathway (i.e. unlabelled) sources for glycogen turnover over this interval. For DS-fed seabass in the present study, we measured a direct pathway contribution of approximately $30 \%$ to hepatic glycogen turnover at $24 \mathrm{~h}$ post-feeding. Based on these results, it is conceivable that the direct pathway contribution could have been higher at earlier times post-feeding but because of the sluggish hepatic glycogen turnover rate, it is, nevertheless, not expected to have a dominating role in postprandial hepatic glycogen levels. In contrast, for juvenile gilthead seabream that were fed over $10 \mathrm{~d}$ with $24 \%$ dietary wheat starch enriched with ${ }^{13} \mathrm{C}$, over two-thirds of hepatic glycogen were estimated to originate from this source ${ }^{(49)}$, suggesting a stronger recruitment of dietary glucose for hepatic glycogen synthesis. Above and beyond systematic methodological differences between the ${ }^{13} \mathrm{C}$-enriched starch and ${ }^{2} \mathrm{H}_{2} \mathrm{O}$ methods, these data may also reflect a more dynamic role of hepatic glycogen turnover and its synthesis from dietary glucose in seabream $v$. seabass.

The quantification of blood glucose and hepatic glycogen sources with ${ }^{2} \mathrm{H}_{2} \mathrm{O}$ is based on the assumption that enrichment of hexose position 2 and PW are equivalent (i.e. H2/ $\mathrm{PW}=1 \cdot 0$ ). For glycogen position 2 enrichment, this assumption may not be correct. Since hepatic glycogen was only partially turned over during ${ }^{2} \mathrm{H}_{2} \mathrm{O}$ administration, the observed glycogen $\mathrm{H} 2 / \mathrm{PW}$ of $0.3-0.5$ is in part explained by preexisting unlabelled glycogen. Hepatic glycogen synthesised from $\left[\mathrm{U}_{-}^{2} \mathrm{H}_{7}\right]$ glucose during a glucose tolerance test retained a significant amount of ${ }^{2} \mathrm{H}$ in position 2 , indicating incomplete exchange with $\mathrm{PW}^{(46)}$. In fasted fish refed with standard fish feed in the presence of ${ }^{2} \mathrm{H}_{2} \mathrm{O}$, the glycogen $\mathrm{H} 2$ :PW ratio was significantly less than $1 \cdot 0$. Under these study conditions, preexisting hepatic glycogen was depleted and, therefore, could not account for the $\mathrm{H} 2 / \mathrm{PW}$ ratio $<1 \cdot 0^{(12)}$. In contrast to hepatic glycogen, blood glucose was completely turned over during the ${ }^{2} \mathrm{H}_{2} \mathrm{O}$-labelling period, and the $\mathrm{H} 2 / \mathrm{PW}$ ratio approached unity under the conditions of endogenous glucose production (CTRL). Therefore, the assumptions that underpin the estimates of blood glucose sources with the ${ }^{2} \mathrm{H}_{2} \mathrm{O}$ method are well supported.

\section{Conclusions}

We demonstrated that incorporation of digestible starch into fish feed results in a significant contribution of absorbed $\mathrm{CHO}$ to endogenous glucose and glycogen fluxes under standard feeding conditions. Hepatic glycogen synthesis is significantly shifted from indirect to direct pathway fluxes; however, these changes seem quantitatively unimportant in terms of overall carbon and nitrogen fluxes. A significant shift in systemic glucose appearance from gluconeogenesis to dietary $\mathrm{CHO}$ absorption can potentially attenuate gluconeogenic amino acid utilisation and $\mathrm{NH}_{3}$ synthesis. However, uncertainties in glucose turnover rates preclude a more precise evaluation of the extent to which amino acid gluconeogenesis is spared by dietary $\mathrm{CHO}$.

\section{Acknowledgements}

The authors acknowledge financial support from Fundação para a Ciência e Tecnologia (FCT) in the form of a fellowship to I. V. (no. SFRH/BPD/90032/2012), a research grant to J. G. J. (No. PTDC/EBB-BIO/098111/2008), and structural funding for the Center for Neurosciences and Cell Biology (no. PEst-C/ SAU/LA0001/2011), also co-funded by the European Regional Development Fund (FEDER) through the programme COMPETE - Operational Competitiveness Programme. The authors also acknowledge financial support in the form of research grants from MCI (Spain) (no. BIO2009-07589) and MEC (Spain) (no. AGL2012-33305; co-funded by the European 
Regional Development Fund, FEDER). The Varian VNMRS $600 \mathrm{MHz}$ spectrometer is part of the National NMR Network (PTNMR) and was purchased in the framework of the National Programme for Scientific Re-equipment (contract REDE/1517/ RMN/2005), with funds from POCI 2010, European Regional Development Fund, and FCT.

The authors' contributions were as follows: I. V., M. A. P., I. V. B. and J. G. J. designed the research; I. V., J. R., I. J., S. L. and A. C.-S. performed the experiments; I. V., I. M., I. V. B. and J. G. J. analysed the data; I. V., I. M., I. V. B. and J. G. J. interpreted the results of the experiments; I. V. and J. G. J. prepared the figures; I. V. and J. G. J. drafted the manuscript; I. V., M. A. P., I. V. B. and J. G. J. edited and revised the manuscript; I. V., I. V. B. and J. G. J. approved the final version of the manuscript.

The authors declare that they have no conflicts of interest, financial or otherwise

\section{References}

1. Gatlin DM, Barrows FT, Brown P, et al. (2007) Expanding the utilization of sustainable plant products in aquafeeds: a review. Aquaculture Res 38, 551-579.

2. Enes P, Panserat S, Kaushik S, et al. (2011) Dietary carbohydrate utilization by European sea bass (Dicentrarchus labrax L.) and Gilthead sea bream (Sparus aurata L.) juveniles. Rev Fish Sci 19, 201-215.

3. Hemre GI, Mommsen TP \& Krogdahl A (2002) Carbohydrates in fish nutrition: effects on growth, glucose metabolism and hepatic enzymes. Aquaculture Nutr 8, 175-194.

4. Stone DAJ (2003) Dietary carbohydrate utilization by fish. Rev Fish Sci 11, 337-369.

5. Adamidou S, Nengas I, Alexis M, et al. (2009) Apparent nutrient digestibility and gastrointestinal evacuation time in European seabass (Dicentrarchus labrax) fed diets containing different levels of legumes. Aquaculture 289, 106-112.

6. Enes P, Panserat S, Kaushik S, et al. (2006) Rapid metabolic adaptation in European sea bass (Dicentrarchus labrax) juveniles fed different carbohydrate sources after heat shock stress. Comp Biochem Physiol A Mol Integr Physiol 145, 73-81.

7. Moreira IS, Peres H, Couto A, et al. (2008) Temperature and dietary carbohydrate level effects on performance and metabolic utilisation of diets in European sea bass (Dicentrarchus labrax) juveniles. Aquaculture 274, 153-160.

8. Peres H \& Oliva-Teles A (2005) Protein and energy metabolism of European seabass (Dicentrarchus labrax) juveniles and estimation of maintenance requirements. Fish Physiol Biochem 31, 23-31.

9. Enes P, Panserat S, Kaushik S, et al. (2006) Effect of normal and waxy maize starch on growth, food utilization and hepatic glucose metabolism in European sea bass (Dicentrarchus labrax) juveniles. Comp Biochem Physiol A Mol Integr Physiol 143, 89-96.

10. Lupatsch I, Kissil GW \& Sklan D (2001) Optimization of feeding regimes for European sea bass Dicentrarchus labrax: a factorial approach. Aquaculture 202, 289-302.

11. Viegas I, Rito J, González JD, et al. (2013) Effects of fooddeprivation and refeeding on the regulation and sources of blood glucose appearance in European seabass (Dicentrarchus labrax L.). Comp Biochem Physiol A Mol Integr Physiol 166, 399-405.
12. Viegas I, Rito J, Jarak I, et al. (2012) Hepatic glycogen synthesis in farmed European seabass (Dicentrarchus labrax L.) is dominated by indirect pathway fluxes. Comp Biochem Physiol A Mol Integr Physiol 163, 22-29.

13. Viegas I, Mendes VM, Leston S, et al. (2011) Analysis of glucose metabolism in farmed European sea bass (Dicentrarchus labrax L.) using deuterated water. Comp Biochem Physiol A Mol Integr Physiol 160, 341-347.

14. Jones JG, Merritt M \& Malloy C (2001) Quantifying tracer levels of ${ }^{2} \mathrm{H}_{2} \mathrm{O}$ enrichment from microliter amounts of plasma and urine by ${ }^{2} \mathrm{H}$ NMR. Magn Reson Med 45, 156-158.

15. Keppler D \& Decker K (1974) Glycogen determination with amyloglucosidase. In Methods of Enzymatic Analysis, pp. 1127-1131 [HU Bergmeyer, editor]. New York: Academic Press, Inc.

16. Caseras A, Metón I, Fernández F, et al. (2000) Glucokinase gene expression is nutritionally regulated in liver of gilthead sea bream (Sparus aurata). Biochim Biophys Acta 1493, $135-141$.

17. Caseras A, Metón I, Vives C, et al. (2002) Nutritional regulation of glucose-6-phosphatase gene expression in liver of the gilthead sea bream (Sparus aurata). Br J Nutr 88, 607-614.

18. Metón I, Mediavilla D, Caseras A, et al. (1999) Effect of diet composition and ration size on key enzyme activities of glycolysis-gluconeogenesis, the pentose phosphate pathway and amino acid metabolism in liver of gilthead sea bream (Sparus aurata). Br J Nutr 82, 223-232.

19. Melo JFB, Lundstedt LM, Metón I, et al. (2006) Effects of dietary levels of protein on nitrogenous metabolism of Rhamdia quelen (Teleostei: Pimelodidae). Comp Biochem Physiol A Mol Integr Physiol 145, 181-187.

20. Viegas I, Caballero-Solares A, Rito J, et al. (2014) Expressional regulation of key hepatic enzymes of intermediary metabolism in European seabass (Dicentrarchus labrax) during food deprivation and refeeding. Comp Biochem Physiol A Mol Integr Physiol 174, 38-44.

21. Pfaffl MW (2001) A new mathematical model for relative quantification in real-time RT-PCR. Nucleic Acids Res 29 e45.

22. Krebs HA (1950) Chemical composition of blood plasma and serum. Annu Rev Biochem 19, 409-430.

23. Enes P, Panserat S, Kaushik S, et al. (2008) Growth performance and metabolic utilization of diets with native and waxy maize starch by gilthead sea bream (Sparus aurata) juveniles. Aquaculture 274, 101-108.

24. Gaye-Siessegger J, Focken U \& Becker K (2006) Effect of dietary protein/carbohydrate ratio on activities of hepatic enzymes involved in the amino acid metabolism of Nile tilapia, Oreochromis niloticus (L.). Fish Physiol Biochem 32 , 275-282.

25. Pérez-Jiménez A, Guedes MJ, Morales AE, et al. (2007) Metabolic responses to short starvation and refeeding in Dicentrarchus labrax. Effect of dietary composition. Aquaculture 265, 325-335.

26. Pérez-Jiménez A, Hidalgo MC, Morales AE, et al. (2009) Use of different combinations of macronutrients in diets for dentex (Dentex dentex): effects on intermediary metabolism. Comp Biochem Physiol A Mol Integr Physiol 152, 314-321.

27. Stanley CA (2009) Regulation of glutamate metabolism and insulin secretion by glutamate dehydrogenase in hypoglycemic children. Am J Clin Nutr 90, 862S-866S.

28. Enes P, Panserat S, Kaushik S, et al. (2008) Rearing temperature enhances hepatic glucokinase but not glucose-6-phosphatase activities in European sea bass (Dicentrarchus labrax) and gilthead sea bream (Sparus aurata) juveniles 
fed with the same level of glucose. Comp Biochem Physiol A Mol Integr Physiol 150, 355-358.

29. Metón I, Caseras A, Fernandez F, et al. (2004) Molecular cloning of hepatic glucose-6-phosphatase catalytic subunit from gilthead sea bream (Sparus aurata): response of its mRNA levels and glucokinase expression to refeeding and diet composition. Comp Biochem Physiol B Biochem Mol Biol 138, 145-153.

30. Panserat S, Medale F, Blin C, et al. (2000) Hepatic glucokinase is induced by dietary carbohydrates in rainbow trout, gilthead seabream, and common carp. Am J Physiol Regul Integr Comp Physiol 278, R1164-R1170.

31. Seiliez I, Panserat S, Lansard M, et al. (2011) Dietary carbohydrate-to-protein ratio affects TOR signaling and metabolism-related gene expression in the liver and muscle of rainbow trout after a single meal. Am J Physiol Regul Integr Comp Physiol 300, R733-R743.

32. Skiba-Cassy S, Panserat S, Larquier M, et al. (2013) Apparent low ability of liver and muscle to adapt to variation of dietary carbohydrate:protein ratio in rainbow trout (Oncorbynchus mykiss). Br J Nutr 109, 1359-1372.

33. Kirchner S, Kaushik S \& Panserat S (2003) Low protein intake is associated with reduced hepatic gluconeogenic enzyme expression in rainbow trout (Oncorbynchus mykiss). J Nutr 133, 2561-2564.

34. Kirchner S, Seixas P, Kaushik S, et al. (2005) Effects of low protein intake on extra-hepatic gluconeogenic enzyme expression and peripheral glucose phosphorylation in rainbow trout (Oncorbynchus mykiss). Comp Biochem Physiol B Biochem Mol Biol 140, 333-340.

35. Wade N, Skiba-Cassy S, Dias K, et al. (2014) Postprandial molecular responses in the liver of the barramundi, Lates calcarifer. Fish Physiol Biochem 40, 427-443.

36. Capilla E, Medale F, Navarro I, et al. (2003) Muscle insulin binding and plasma levels in relation to liver glucokinase activity, glucose metabolism and dietary carbohydrates in rainbow trout. Regul Pept 110, 123-132.

37. Enes P, Panserat S, Kaushik S, et al. (2008) Hepatic glucokinase and glucose-6-phosphatase responses to dietary glucose and starch in gilthead sea bream (Sparus aurata) juveniles reared at two temperatures. Comp Biochem Physiol A Mol Integr Physiol 149, 80-86.

38. Couto A, Enes P, Peres H, et al. (2008) Effect of water temperature and dietary starch on growth and metabolic utilization of diets in gilthead sea bream (Sparus aurata) juveniles. Comp Biochem Physiol A Mol Integr Physiol 151, 45-50.

39. González JD, Caballero A, Viegas I, et al. (2012) Effects of alanine aminotransferase inhibition on the intermediary metabolism in Sparus aurata through dietary amino-oxyacetate supplementation. Br J Nutr 107, 1747-1756.

40. Dias J, Rueda-Jasso R, Panserat S, et al. (2004) Effect of dietary carbohydrate-to-lipid ratios on growth, lipid deposition and metabolic hepatic enzymes in juvenile Senegalese sole (Solea senegalensis, Kaup). Aquaculture Res 35, 1122-1130.
41. Figueiredo-Silva AC, Corraze G, Rema P, et al. (2009) Blackspot seabream (Pagellus bogaraveo) lipogenic and glycolytic pathways appear to be more related to dietary protein level than dietary starch type. Aquaculture 291, 101-110.

42. Peres H \& Oliva-Teles A (2002) Utilization of raw and gelatinized starch by European sea bass (Dicentrarchus labrax) juveniles. Aquaculture 205, 287-299.

43. Panserat S, Medale F, Breque J, et al. (2000) Lack of significant long-term effect of dietary carbohydrates on hepatic glucose-6-phosphatase expression in rainbow trout (Oncorbynchus mykiss). J Nutr Biochem 11, 22-29.

44. Panserat S, Plagnes-Juan E \& Kaushik S (2002) Gluconeogenic enzyme gene expression is decreased by dietary carbohydrates in common carp (Cyprinus carpio) and gilthead seabream (Sparus aurata). Biochim Biophys Acta 1579, 35-42.

45. Kamalam BS, Medale F, Kaushik S, et al. (2012) Regulation of metabolism by dietary carbohydrates in two lines of rainbow trout divergently selected for muscle fat content. J Exp Biol 215, 2567-2578.

46. Martins FO, Rito J, Jarak I, et al. (2013) Disposition of $\left[\mathrm{U}_{-}^{2} \mathrm{H}_{7}\right]$ glucose into hepatic glycogen in rat and in seabass. Comp Biochem Physiol A Mol Integr Physiol 166, 316-322.

47. Dai W, Panserat S, Mennigen J, et al. (2013) Postprandial regulation of hepatic glucokinase and lipogenesis requires the activation of TORC1 signaling in rainbow trout (Oncorbynchus mykiss). J Exp Biol 216, 4483-4492.

48. Fernández F, Miquel AG, Córdoba M, et al. (2007) Effects of diets with distinct protein-to-carbohydrate ratios on nutrient digestibility, growth performance, body composition and liver intermediary enzyme activities in gilthead sea bream (Sparus aurata, L.) fingerlings. J Exp Mar Bio Ecol 343, $1-10$.

49. Ekmann KS, Dalsgaard J, Holm J, et al. (2013) Glycogenesis and de novo lipid synthesis from dietary starch in juvenile gilthead sea bream (Sparus aurata) quantified with stable isotopes. Br J Nutr 109, 2135-2146.

50. Felip O, Ibarz A, Fernández-Borràs J, et al. (2012) Tracing metabolic routes of dietary carbohydrate and protein in rainbow trout (Oncorbynchus mykiss) using stable isotopes $\left(\left[{ }^{13} \mathrm{C}\right]\right.$ starch and $\left[{ }^{15} \mathrm{~N}\right]$ protein): effects of gelatinisation of starches and sustained swimming. Br J Nutr 107, 834-844.

51. Ekmann KS, Dalsgaard J, Holm J, et al. (2013) Effects of dietary energy density and digestible protein:energy ratio on de novo lipid synthesis from dietary protein in gilthead sea bream (Sparus aurata) quantified with stable isotopes. BrJ Nutr 110, 1771-1781.

52. Felip O, Blasco J, Ibarz A, et al. (2013) Beneficial effects of sustained activity on the use of dietary protein and carbohydrate traced with stable isotopes ${ }^{15} \mathrm{~N}$ and ${ }^{13} \mathrm{C}$ in gilthead sea bream (Sparus aurata). J Comp Physiol B 183, 223-234.

53. Enes P, Sanchez-Gurmaches J, Navarro I, et al. (2010) Role of insulin and IGF-I on the regulation of glucose metabolism in European sea bass (Dicentrarchus labrax) fed with different dietary carbohydrate levels. Comp Biochem Physiol A Mol Integr Physiol 157, 346-353. 